\title{
IoT Smart Home Adoption: The Importance of Proper Level Automation
}

\author{
Heetae Yang, ${ }^{1}$ Wonji Lee, ${ }^{2}$ and Hwansoo Lee $\mathbb{D}^{3}$ \\ ${ }^{1}$ Science and Technology Policy Institute, Sejong National Research Complex, 370 Sicheong-daero, Sejong-si 30147, Republic of Korea \\ ${ }^{2}$ Interdisciplinary Graduate Program in IT Law, Dankook University, 152 Jukjeon-ro, Suji-gu, Yongin-si, \\ Gyeonggi-do 16890, Republic of Korea \\ ${ }^{3}$ Department of Convergence Security, Dankook University, 152 Jukjeon-ro, Suji-gu, Yongin-si, Gyeonggi-do 16890, Republic of Korea
}

Correspondence should be addressed to Hwansoo Lee; hanslee992@gmail.com

Received 13 November 2017; Accepted 9 May 2018; Published 22 May 2018

Academic Editor: Mucheol Kim

Copyright (c) 2018 Heetae Yang et al. This is an open access article distributed under the Creative Commons Attribution License, which permits unrestricted use, distribution, and reproduction in any medium, provided the original work is properly cited.

\begin{abstract}
The word "smart" has been used in various fields and is widely accepted to mean intelligence. Smart home service, one of the representative emerging technologies in the IoT era, has changed house equipment into being more intelligent, remote controllable, and interconnected. However, the intelligence and controllability of a smart home service are contradictory concepts, under certain aspects. In addition, the level of intelligence or controllability of a smart home service that users want may differ according to the user. As potential users of smart home services have diversified in recent years, providing the appropriate functions and features is critical to the diffusion of the service. Thus, this study examines the smart home service features that current users require and empirically evaluates the relationship between the critical factors and the adoption behavior with 216 samples from Korea. The moderating effect of personal characteristics on behavior is also tested. The results of the analysis provide various theoretical and practical implications.
\end{abstract}

\section{Introduction}

We are experiencing a new era of Internet of Things (IoT), where many electronic devices surrounding us are interconnected by a network [1]. This paradigm enables copious amounts of data to be stored, processed, and conferred in a proficiently interpretable form without human invention. The emerging of IoT also sheds new light on the concept of a "smart home." IoT-enabled house equipment allows for a smart home to be more intelligent, remote controllable, and interconnected.

The global smart home market is expected to grow to USD 119.26 billion by 2022 [2]. Global companies (e.g., Google, Amazon, and Samsung Electronics) are entering this huge market, and they are providing innovative services and products to take advantage of the growing market. Many start-ups are also making efforts to join this growing market. The smart home has been drawing attention recently due to the IoT, but it is not a new concept. In fact, the concept of a smart home has been discussed since 1980, and it has evolved from traditional home automation (so-called networked homes, ubiquitous homes, and intelligent and interactive homes).

Despite the long history and growing interest, smart home service has not been widely accepted. There are many reasons (e.g., high device prices, limited consumer demand, and long device replacement cycles) preventing smart home diffusion. The largest barrier is due to a lack of technology to establish the infrastructure of a smart home [3]. Edwards and Grinter [4] argued that another reason is that the issues and social aspects of adoption and diffusion of a smart home service have been overlooked. Prior studies on smart homes have been conducted without reflecting user characteristics or their environments. Most approaches are based on experiments or solely focused on the technology. Technological or engineering perspectives on smart homes have failed to interpret potential users' actual needs from a smart home.

Thus, this research aims to find what users really want from smart home services and investigate which features affect a user's intention to leverage the service. This study will 
TABLE 1: Evolution of smart home services.

\begin{tabular}{lccc}
\hline Year & Phase & Technical background & Main function \\
\hline $1990 \mathrm{~s}$ & Home automation & Broadband Internet & Household automation \\
$2000 \mathrm{~s}$ & Home network & Smart phone and app & Remote monitoring \& control \\
$2010 \mathrm{~s}$ & Smart home & IoT \& AI & Context awareness \\
\hline
\end{tabular}

define the user acceptance factors from a new perspective and present a theoretical model to verify precedent factors and outcomes. Through this empirical and behavioral analysis, it will determine the concept of "smart" as reflecting a user's actual smart home needs and its major functional features. In order to confirm that the needs for smartization sought by people vary depending on their individual characteristics and environment, the research also studies how aspects including the type of housing, gender, age, and prior experience affect user intentions.

\section{Related Background}

2.1. Smart Home. A smart home refers to a residence equipped with a communication network, high-tech household devices, appliances, and sensors that can be remotely accessed, monitored, and controlled and that provide services responding to the residents' needs [5]. Although the widespread diffusion of high-speed Internet in the late 1990s provided the opportunity for the home network business to grow, it was not until the late 2000s that smart homes began to be installed, which is when smart phones were popularized. Initially, a smart home was defined using various names, such as a home network, a digital home, home automation, and an intelligent home. In the mid2010s, it has been leaning towards a combination of Internet of Things (IoT) and a situation-aware smart home (Table 1).

A smart home is an advanced form of traditional home automation. An early definition of a smart home, which was influenced by home automation, is using common communication devices to integrate with a variety of services at home, assuring economic, secure, and comfortable operation of the home [6]. Thus, smart home service was used to manage environmental systems like lighting and heating [3]. These days due to technological development, a smart home service monitors user activities and the internal environment at home (Figure 1). Moreover, a smart home provides services that fulfill the demands and needs of a user.

Recently, smart home services are evolving as they approach AI. The intelligent personal assistant "Alexa," developed by Amazon Lab126, has been installed in a wide range of products. LG Electronics has adopted Alexa throughout its smart home product line. For example, if a user calls "Alexa" from a smart refrigerator, the user can access services such as searching news, online shopping, and checking schedules. In addition, China smart home manufacturer Xiaomi is planning to target the smart home market as part of its long-term vision. Xiaomi launched an air purifier that can be remotely controlled by a smart phone and developed a smart module that can be inserted into all appliances such as refrigerators, air conditioners, and washing machines. Apple is developing an AI speaker that supports "Apple HomeKit," expected to provide voice support as a hub to control home kit products. Thus, smart home services are developing and proliferating by adopting IoT and AI.

Prior studies on smart homes are based on a technical or a partial approach. For instance, [7] suggested a smart floor technology for a smart home which examines who, where, and what a user is doing. Adami et al. [8] proposed a wrist gadget that monitors users' habits at home. Andoh et al. [9] suggested a biometrics monitoring system for analyzing the pulse and respiratory rate at home. Koskela and VäänänenVainio-Mattila [10] conducted experiments with only young nontechnical professionals to determine whether users welcome smartness through familiar communication devices such as PCs, TVs, and mobile phones. Paetz et al. [11] proposed an automated energy management system to test residents. These studies have contributed greatly to improve the completeness of a smart home service. However, as research on business and user perspectives for market revitalization was lacking, more studies are requisite to encourage the proliferation of smart home services.

\subsection{Smart Home Service Adoption. The word "smart" has} been used in various fields such as smart phones, smart TVs, and smart learning, including smart homes. Although it has a slightly different meaning in each concept, it generally means "intelligent," which can be interpreted as the concept of a weak level of artificial intelligence (AI). However, whether such a concept represents an intelligence service that can perfectly substitute the decision-making process of human beings requires debate. Humans in general will be reluctant to delegate all of the decision-making authority to machines considering their search for freedom, uncertainty, and distrust in technology. In addition, the level of smartness people demand would also vary depending on their individual characteristics and environment. Some people have vague fears about intelligent and smart things. For instance, when AlphaGo beat a human in the Go game, some people had negative perspectives on AI because a computer can control or be detrimental to people. Thus, the "smart" that people want may entail a limited scope of intelligence which is under the control of human beings, unlike the theoretical point of view.

Smart home service acceptance research has been active since the mid-2000s. Most studies have extended the technology acceptance model (TAM) or the unified theory of acceptance and use of technology (UTAUT) and have focused on specific groups such as the elderly, the disabled, and patients. Leeraphong et al. [12] demonstrated that self-efficacy plays an important role in the 


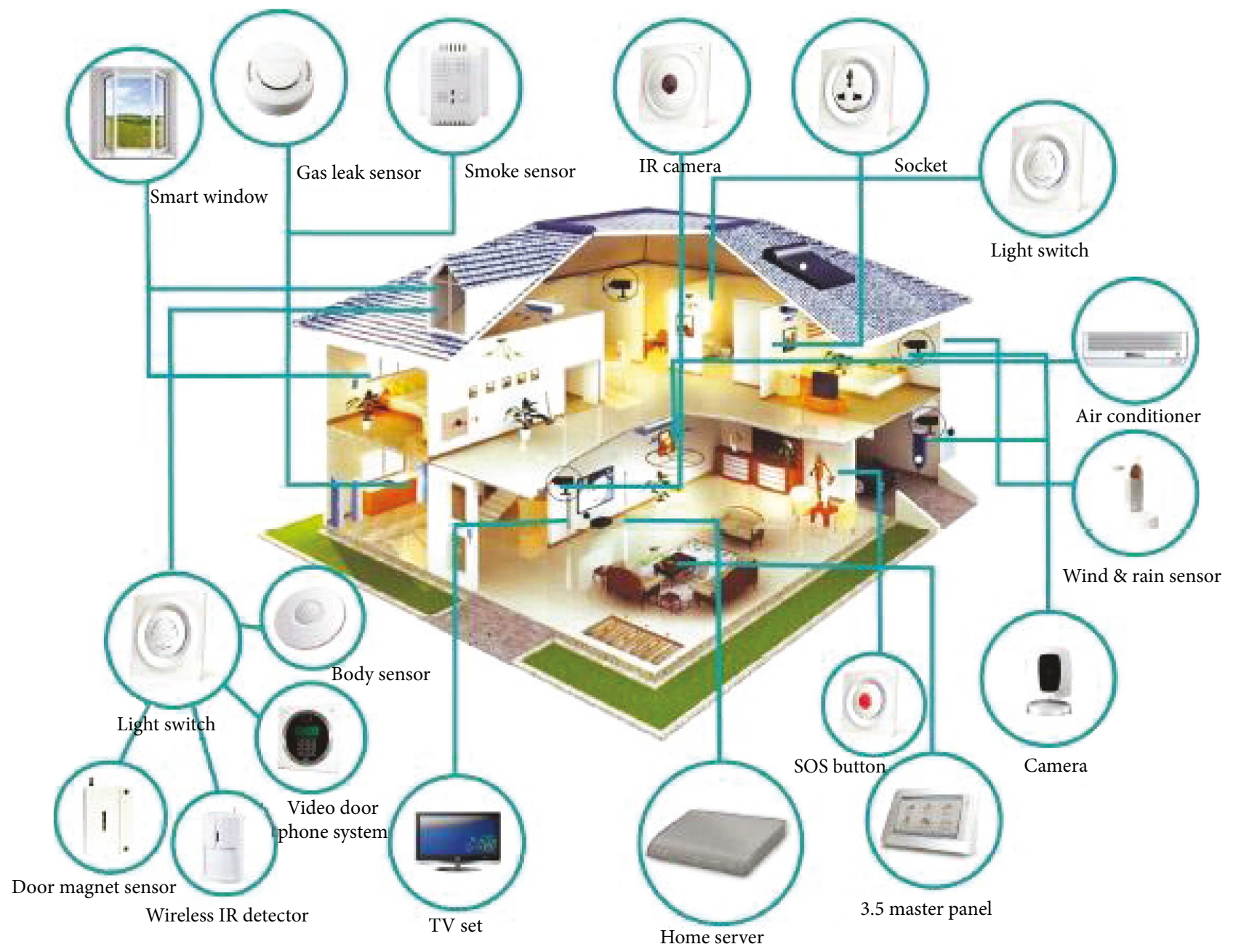

FIGURE 1: Smart Home (http://smarthomeenergy.co.uk).

acceptance of a smart home for the elderly. In the Alaiad and Zhou study [13], patients' expectations of quality of life were found to play a key role in smart home acceptance. While expanding on the existing theories, attempts have been made to search for new factors. Fan et al. [14] mentioned the continued development of AAL (ambient assisted living) which assists disabled and elderly people especially with chronic diseases, to enhance their well-being and enable independent living. Vadillo et al. [15] conducted research on telecare system adoption, which is one type of smart home service, and found perceived usefulness is important for the intention to use the system.

Recently, as smart services become more common, research on the acceptance of general users has become active. Bao et al. [16] examined the mobile smart home environment and found that compatibility and safety are key factors affecting mobile smart home acceptance. Park et al. [17] foresee that the future concept of smart home acceptance with IoT technologies will expand by presenting accessibility to wireless networks, as well as the compatibility of various operation systems, languages, and frameworks. Furthermore, this study empirically proved that enjoyment, compatibility, connectedness, control, and cost can motivate the acceptance of a smart home. Ji et al. [18] pointed out that controllability is significant in adopting a smart home. In addition, intelligent control is able to learn user behavior and demand automatically and provide a smarter control of appliances.

Some studies emphasize the importance of security and privacy in smart home acceptance. For instance, Tanwar et al. [19] identified that the level of security in households is distinctively conceivable in accepting a smart home service. Elmasllari and Al-Akkad [20] argued that clear privacy and data protection is needed to operate smart energy systems. La Marra et al. [21] stated that security and safety risks which affect user behavior can also be mitigated by adding configurable systems for security policy enforcement.

However, as the existing discussions are abstract, a fundamental understanding is necessary to characterize smart home services. In addition, past studies have conducted an empirical analysis on a specific group, but the popularization of smart home services now requires more general discussions for diverse user classes.

2.3. Critical Factors for Smart Home Service. The initial smart home service was promoted through the automation of the 
domestic system, aiming for convenience, comfort, stability, amenity, health, reduction of household labor, and energy efficiency. Since then, developments of the wireless Internet and smart phones have extended the concept of a smart home to services that can be remotely controlled anytime and anywhere. In the IoT era, household electrical appliances and information and communication devices are interconnected, and the smart home is developing into a form of an artificial intelligence service that operates by self-understanding the behaviors of the residents. Therefore, the smart home in the IoT era is a concept that adds interconnectedness to the traditional characteristics of automation and remote controllability [22]. Service stability, security, and privacy also have been suggested as important factors that may hinder user acceptance [23]. These factors can be summarized as the reliability of the service. The smart home environment is a factor that must be considered because it is closely related to the user's life and can cause serious damage in the case of a dangerous situation. Thus, automation, remote controllability, interconnectedness, and reliability can be summarized as crucial factors for accepting a smart home service.

Automation is defined as the "execution by a machine agent (usually a computer) of a function that was previously carried out by human" [24]. Home automation was the initial name of the smart home service, and the automation of households and home infrastructure was a key goal of the early smart home. Automation has become prominent in recent years because it has become more affordable and simple through the development of information technology. In recent years, an interest in AI has enabled higher-level automation. AI technology can advance the function of a smart home by assisting users in an intelligent way [25]. Hence, technology is one of the critical features of a smart home.

The virtue of a smart home is that it can be controlled remotely by mobile devices. This is a core feature of a smart home system since users prefer to instantly control smart home services such as controlling lamps, curtains, and information appliances [10]. However, to design an intelligent and remote-controllable smart home system, a network connection is essential. Many networks exist with a variety of features such as Bluetooth IEEE 802.15.4, Z-Wave, and Wi-Fi. To enable remote control, networks should be standardized and interconnected to expand the use of smart home services. Most electronic devices support the Wi-Fi protocol, which allows home devices to be controlled by mobile devices. When remote control is possible, the general concept of smart, anywhere and anytime, can actually be implemented.

Interconnectedness is defined as the ability of devices, applications, and services to be connected with each other to work together [26]. To proliferate a smart home, devices should able to adapt to changes in the preferences, requirements, and needs of a user [4]. The system should easily connect to new devices in a smart home. It is critical to correspond through the network for a smart home to function properly. However, many types of network and communication protocols are a barrier in reality [5]. Networks can be wired or wireless, and other types of communications exist. At present, the technical standard is inadequate due to the high cost of satellite links and the limited transmission between electronic devices [27].

Technical errors in integrated smart homes can be a concern to potential users. The reliability of smart home services depends not only on the fact that the technology will not malfunction but also on the fact that the technological components will function flawlessly while providing an accurate service [5]. Users' trust in service providers is an important issue for the diffusion of smart home services. Currently, technologies for smart homes are limited to predicting human behavior. Smart home services must be able to provide reliable measurements and algorithms to assess a user's vital signs or lifestyle [27].

\section{Research Model and Hypotheses Development}

The research model of this study was developed as shown in Figure 2, with the following essential antecedent factors that affect a user's intentions for smart home services: automation, controllability, interconnectedness, and reliability.

3.1. Perceived Automation. Automation is a term referring to the automation of housework and household activities such as the control of lighting, heating systems, and ventilation. This kind of automation enables users to be comfortable, live conveniently, be secure, and be energy efficient. In addition, it monitors elderly and disabled people to ensure suitable care [28]. The acceptance of automation has increased in smart homes recently due to the enhanced affordability and simplicity through upgraded technology [29]. Sági et al. [28] proposed a controller to optimize power management to reduce the energy consumption of a smart home automation system. Luor et al. [29] authenticated the correlation between the user attitude and efficient smart home automation function.

H1: perceived automation is positively associated with smart home adoption intention.

3.2. Perceived Controllability. Controllability is the ability to do whatever a user needs with the given system that is under control [30]. Liu et al. [31] confirmed that control is a critical issue in most complex networks. Users remotely control smart home systems by accessing services on smartphones, mobile phones, and computers [32, 33]. Due to the increased number of sensors and multitouch screens, mobile devices became a pivotal user interface in smart home systems [34]. In addition, Roduner et al. [35] implicated that user interfaces on mobile devices are key for controlling a smart home system.

$H 2$ : perceived controllability is positively associated with smart home adoption intention.

3.3. Perceived Interconnectedness. Interconnectedness is defined as the ability to work together reliably owing to the fact that a discrete manufacturer exists [26]. Many studies have revealed the importance of interconnectedness while adopting new IT services. The study by [36] defined that 


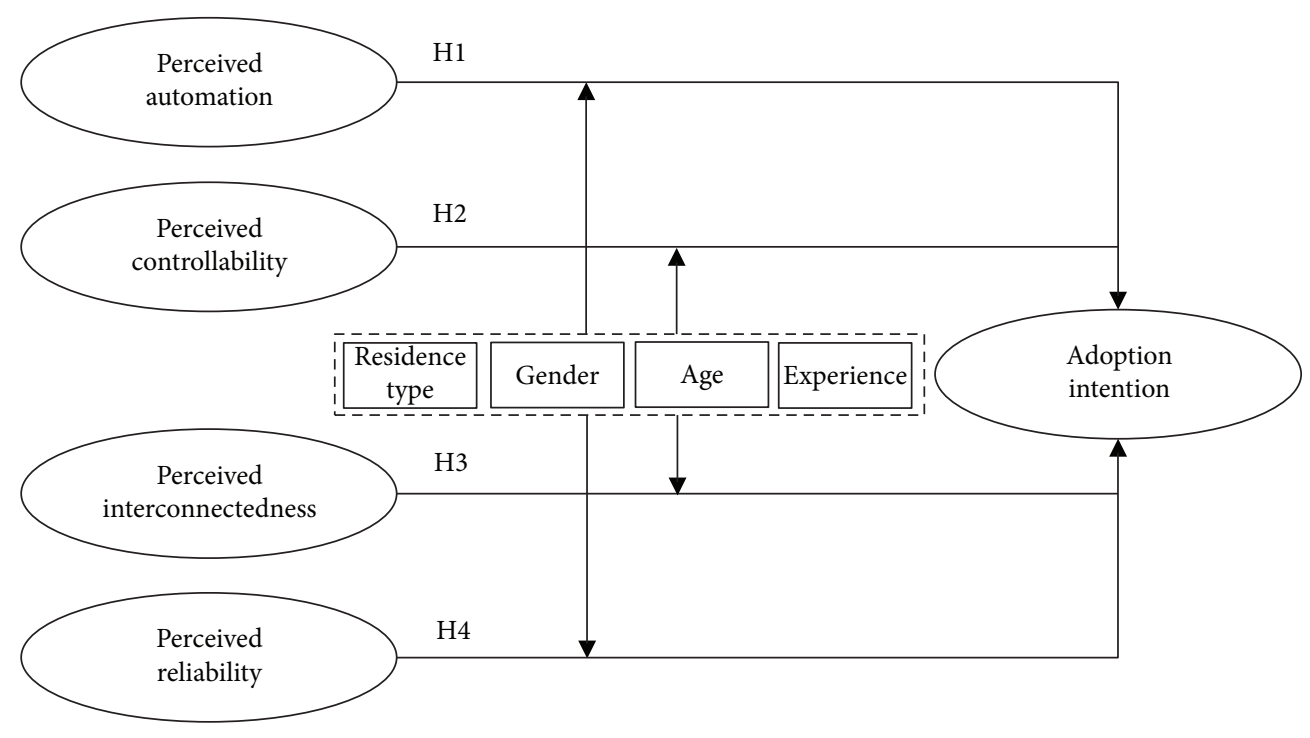

Figure 2: Research model.

compatibility was a key component in perceiving the efficiency of mobile multimedia services. Yang et al. [37] pointed out that technical compatibility affects users' perceived usefulness of wearable devices. IoT applications or services cannot be said to be smart home simply because other devices monitor or adjust one home application, sensor, or device. Since the interworking of multiple devices and a central device is essential, a smart home system requires a platform to provide a common framework [27].

H3: perceived interconnectedness is positively associated with smart home adoption intention.

3.4. Perceived Reliability. Reliability between a manufacturer and a user is an important factor in user behavior. In the Maslow theory of human motivation safety, security and protection are the second needs to be satisfied after fulfilling basic physiological needs like food, water, and shelter [38]. Services like alarms and at-home security should be operating properly. Keen et al. [39] suggested that e-commerce represents a strategic indication of trust for consumermarketer relationships. Chan et al. [27] indicated the reliability of a sensor and data processing system as a one of main determining factors of adopting a smart home. Friedewald et al. [40] verified that a smart home system should aim to be dependable which leads to successful innovation from the socioeconomic and technological constellation.

H4: perceived reliability is positively associated with smart home adoption intention.

Smart home services are no longer a specialized service for a specific group of people such as housewives, patients, or the elderly but are now developing into a more public service that the general public can use for a more convenient lifestyle. Such trends call for the need of a more detailed analysis of the actual motivations of diverse groups of users in order to generalize the research results and render them a reflection of the current times. As there could be a difference in the relationship between variables representing conventional users and new groups
TABLE 2: Characteristics of the respondents.

\begin{tabular}{|c|c|c|}
\hline \multirow{2}{*}{ Characteristics } & \multicolumn{2}{|c|}{ Respondents $(n=216)$} \\
\hline & Number & Percentage \\
\hline \multicolumn{3}{|l|}{ Gender } \\
\hline Male & 111 & 51.4 \\
\hline Female & 105 & 48.6 \\
\hline \multicolumn{3}{|l|}{ Age } \\
\hline $16-19$ & 28 & 13.0 \\
\hline $20-29$ & 37 & 17.1 \\
\hline $30-39$ & 45 & 20.8 \\
\hline $40-49$ & 46 & 21.2 \\
\hline $50-59$ & 38 & 17.5 \\
\hline $60+$ & 22 & 10.4 \\
\hline \multicolumn{3}{|l|}{ Education } \\
\hline Less than high school & 44 & 20.4 \\
\hline College or university & 150 & 69.4 \\
\hline Advanced degree & 22 & 10.2 \\
\hline \multicolumn{3}{|l|}{ Occupation } \\
\hline Official worker & 60 & 27.8 \\
\hline Service worker & 8 & 3.7 \\
\hline Professional/researcher & 12 & 5.5 \\
\hline Self-employer & 14 & 6.5 \\
\hline Public service worker & 3 & 1.4 \\
\hline Student & 66 & 30.6 \\
\hline Housewife & 34 & 15.7 \\
\hline Other & 19 & 8.8 \\
\hline \multicolumn{3}{|l|}{ Residence type } \\
\hline Apartment/multifamily house & 114 & 52.8 \\
\hline Single house & 102 & 47.2 \\
\hline \multicolumn{3}{|l|}{ Experience of smart home service } \\
\hline Yes & 46 & 21.3 \\
\hline No & 170 & 78.7 \\
\hline
\end{tabular}


of users when considering their characteristics, the research investigated the differences between groups according to the type of housing, gender, age, and use experience, as moderator variables.

\section{Research Method}

4.1. Data. This study conducted an online survey in October 2015 to evaluate the research model. Data was collected by a professional survey company in Korea. The final 216 collected samples were used for analysis. The demographic distribution of the samples is as follows: 111 males $(51.4 \%)$, 105 females (48.6\%), 10s (28, 13\%), 20s (37, 17.1\%), 30s $(45,20.8 \%), 40$ s $(46,21.2 \%), 50 s(38,17.5 \%)$, and over 60
$(22,10.4 \%)$. The distribution of the samples was balanced for analysis (Table 2).

4.2. Instrument Development. All measurement items to measure latent constructs were developed based on previous studies. Responses were collected based on a 5-point Likert scale. The items of each construct are shown in Table 3. The PLS-SEM (partial least squares structural equation modeling) analysis method and the Smart PLS 2.0 tool were used to verify the research hypotheses after testing the convergent validity of each construct and discriminant validity. Furthermore, in order to compare the route coefficients according to the residence type, sex, age, and experience, we use the following formula given by Chin and Dibbern [41].

$$
t=\frac{\text { Path }_{\text {sample1 }}-\text { Path }_{\text {sample2 }}}{\sqrt{\left((m-1)^{2} /(m+n-2)\right) \times \text { s.e. }^{2}{ }_{\text {sample1 }}+\left((n-1)^{2} /(m+n-2)\right) \times \text { s.e. }_{\text {sample2 }}^{2}} \times \sqrt{(1 / m)+(1 / n)}} \sim t_{m+n-2}
$$

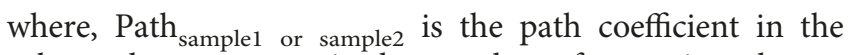
subsample 1 or $2, m$ is the number of cases in subsample $1, n$ is the number of cases in subsample 2, and

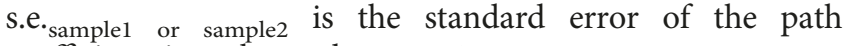
coefficient in subsample 1 or 2 .

\section{Data Analysis and Results}

5.1. Measurement Model. The reliability and validity of the constructs were checked. The reliability of latent variables can be confirmed by Cronbach's $\alpha$ and composite reliability (CR). Generally, reliability is considered to be satisfied when Cronbach's $\alpha$ exceeds 0.7 [49]. Even though Cronbach's $\alpha$ for perceived controllability and perceived reliability are lower than 0.7 , the CR value was sufficiently big, so there was no significant problem in reliability (Table 4). Confirmatory factor analysis was conducted to test the convergent validity of each construct. In Table 4, all factor loadings exceeded 0.6 , the minimum required to assure convergent validity of the constructs [50], and the AVE for each construct exceeded 0.50 [51]. As a result, convergent validity is established. Discriminant validity was demonstrated by confirming that the square root of the average variance extracted (AVE) for each construct is higher than the corresponding interconstruct correlations. There was no critical issue in cross-loading for the discriminant validity (see Tables 5 and 6).

5.2. Hypotheses Testing. Structural equation modelling results are presented in Figure 3, and the hypothesis tests are summarized in Table 4. A bootstrapping resampling technique was employed to calculate the corresponding $t$-values for each hypothesized relationship. As summarized in Figure 3, in the analysis of the whole sample, out of the 4 hypotheses, three were supported. Perceived controllability, perceived interconnectedness, and perceived reliability were significant factors influencing adoption intention, supporting $\mathrm{H} 2, \mathrm{H} 3$, and $\mathrm{H} 4$, and explaining $47.9 \%$ of the variance $(\mathrm{H} 2: \beta=0.327, t$-value $=3.170$, and $p<0.001$; H3: $\beta=0.232, t$-value $=2.363$, and $p<0.05$; and H4: $\beta=$ $0.154, t$-value $=2.642$, and $\left.p<0.01 ; R^{2}=0.479\right)$. However, the path from perceived automation to adoption intention was insignificant, rejecting $\mathrm{H} 1$.

However, the results were very diverse when analyzed by grouping according to the residence type, gender, age, and experience (Table 7). For example, in the analysis for general home residents, $\mathrm{H} 1, \mathrm{H} 2$, and $\mathrm{H} 4$ were supported but $\mathrm{H} 3$ was not. On the other hand, only $\mathrm{H} 2$ and $\mathrm{H} 3$ were supported for apartment residents. In terms of gender, $\mathrm{H} 2$ and $\mathrm{H} 3$ were supported in males but $\mathrm{H} 2$ and $\mathrm{H} 4$ were supported in females. When analyzed by age, $\mathrm{H} 2$ and $\mathrm{H} 3$ were supported by those under the age of 39 but $\mathrm{H} 2$ was supported only by those over 40 years of age. $\mathrm{H} 1$ and $\mathrm{H} 4$ were supported for current smart home service users, and $\mathrm{H} 2$ and $\mathrm{H} 3$ were supported for potential users.

\section{Discussion}

6.1. Findings. The objective of this study was to understand and explain customers' behavioral intentions to adopt smart home services. Unlike the previous research that examined the user behavior associated with smart home service adoption based on acceptance theories, this study captures the characteristics of smart home services and presents a new theory and model. The empirical analysis of the proposed research model demonstrated various implications.

In all samples, three factors: controllability, interconnectedness, and reliability had a significant impact on the acceptance behavior of a smart home service. It is very interesting that automation does not have a significant effect. This can be interpreted as follows: people generally seek relatively safer 
TABLE 3: Survey items.

\begin{tabular}{|c|c|c|c|}
\hline Construct & Item number & Measurement items & References \\
\hline \multirow{2}{*}{ Perceived automation } & PA1 & Smart home services help the residents proactively without human intervention. & \multirow{2}{*}[29,42]{} \\
\hline & $\mathrm{PA} 2$ & Smart home services provide autoadjusted control. & \\
\hline \multirow[t]{2}{*}{ Perceived controllability } & PC1 & $\begin{array}{l}\text { I can control every electrical device of smart home services } \\
\text { through simple operation. }\end{array}$ & \multirow[t]{2}{*}[43,44]{} \\
\hline & PC2 & It is convenient to control smart home services anywhere at any time. & \\
\hline \multirow[b]{2}{*}{ Perceived interconnectedness } & PI1 & Smart home devices are interconnected with each other. & \multirow[b]{2}{*}[45,46]{} \\
\hline & PI2 & $\begin{array}{l}\text { Smart home services by integrating different device venders } \\
\text { do not create problems. }\end{array}$ & \\
\hline \multirow{3}{*}{ Perceived reliability } & PR1 & $\begin{array}{l}\text { I am not worried to use smart home services because other people or } \\
\text { organizations may be able to access my account. }\end{array}$ & \multirow{3}{*}[43,47]{} \\
\hline & PR2 & $\begin{array}{l}\text { There will not be much potential loss associated with disclosing } \\
\text { personal information to the smart home service provider. }\end{array}$ & \\
\hline & PR3 & I think smart home service providers are reliable. & \\
\hline \multirow{3}{*}{ Adoption intention } & AI1 & Using smart home services is worthwhile. & \multirow{3}{*}[48]{} \\
\hline & $\mathrm{AI} 2$ & I intend to use smart home services in the future. & \\
\hline & $\mathrm{AI} 3$ & I predict I would use smart home services in the future. & \\
\hline
\end{tabular}

TABLE 4: Validity of constructs.

\begin{tabular}{|c|c|c|c|c|c|c|}
\hline Construct & Items & Factor loading & $t$-value & $\operatorname{AVE}(>0.5)$ & Composite reliability $(>0.6)$ & Cronbach's alpha $(>0.7)$ \\
\hline \multirow{2}{*}{ Perceived automation } & $\mathrm{PA} 1$ & 0.947 & 97.763 & \multirow{2}{*}{0.902} & \multirow{2}{*}{0.965} & \multirow{2}{*}{0.946} \\
\hline & $\mathrm{PA} 2$ & 0.954 & 119.742 & & & \\
\hline \multirow{2}{*}{ Perceived controllability } & PC1 & 0.898 & 61.407 & \multirow{2}{*}{0.903} & \multirow{2}{*}{0.949} & \multirow{2}{*}{0.893} \\
\hline & PC2 & 0.831 & 23.021 & & & \\
\hline \multirow{2}{*}{ Perceived interconnectedness } & PI1 & 0.935 & 94.090 & \multirow{2}{*}{0.748} & \multirow{2}{*}{0.855} & \multirow{2}{*}{0.667} \\
\hline & PI2 & 0.902 & 38.725 & & & \\
\hline \multirow{3}{*}{ Perceived reliability } & PR1 & 0.714 & 7.651 & \multirow{3}{*}{0.843} & \multirow{3}{*}{0.915} & \multirow{3}{*}{0.815} \\
\hline & PR2 & 0.769 & 9.760 & & & \\
\hline & PR3 & 0.769 & 12.624 & & & \\
\hline \multirow{3}{*}{ Adoption intention } & CONT1 & 0.947 & 114.355 & \multirow{3}{*}{0.564} & \multirow{3}{*}{0.795} & \multirow{3}{*}{0.647} \\
\hline & CONT2 & 0.964 & 163.208 & & & \\
\hline & CONT3 & 0.938 & 101.322 & & & \\
\hline
\end{tabular}

TABLE 5: Correlations of the constructs and square root of AVE.

\begin{tabular}{lccccc}
\hline & PA & PC & PI & PR & AI \\
\hline PA & $\mathbf{0 . 9 0}$ & & & & \\
PC & 0.68 & $\mathbf{0 . 8 6}$ & & & \\
PI & 0.54 & 0.78 & $\mathbf{0 . 9 2}$ & & \\
PR & 0.36 & 0.56 & 0.51 & $\mathbf{0 . 7 5}$ & \\
AI & 0.50 & 0.66 & 0.62 & 0.49 & $\mathbf{0 . 9 5}$ \\
\hline
\end{tabular}

and more effective remote management features rather than highly advanced automated services. People may want the devices of a smart home to be under their control rather than being fully automated because a home is safe and represents their personal space where they can rest. Considering that controllability is the most important antecedent for adoption, it becomes apparent that the automation that people
TABLE 6: Construct cross-loadings.

\begin{tabular}{lccccc}
\hline & PA & PC & PI & PR & AI \\
\hline PA1 & $\mathbf{0 . 9 4 7}$ & 0.637 & 0.492 & 0.355 & 0.457 \\
PA2 & $\mathbf{0 . 9 5 4}$ & 0.650 & 0.540 & 0.334 & 0.486 \\
\hline PC1 & 0.716 & $\mathbf{0 . 8 9 8}$ & 0.615 & 0.513 & 0.629 \\
PC2 & 0.426 & $\mathbf{0 . 8 3 1}$ & 0.757 & 0.448 & 0.497 \\
\hline PI1 & 0.543 & 0.735 & $\mathbf{0 . 9 3 5}$ & 0.480 & 0.616 \\
PI2 & 0.448 & 0.696 & $\mathbf{0 . 9 0 2}$ & 0.453 & 0.507 \\
\hline PR1 & 0.162 & 0.321 & 0.303 & $\mathbf{0 . 7 1 4}$ & 0.249 \\
PR2 & 0.188 & 0.285 & 0.301 & $\mathbf{0 . 7 6 9}$ & 0.308 \\
PR3 & 0.389 & 0.564 & 0.482 & $\mathbf{0 . 7 6 9}$ & 0.472 \\
\hline AI1 & 0.446 & 0.581 & 0.553 & 0.437 & $\mathbf{0 . 9 4 7}$ \\
AI2 & 0.482 & 0.662 & 0.598 & 0.463 & $\mathbf{0 . 9 6 4}$ \\
AI3 & 0.484 & 0.625 & 0.602 & 0.490 & $\mathbf{0 . 9 3 8}$ \\
\hline
\end{tabular}




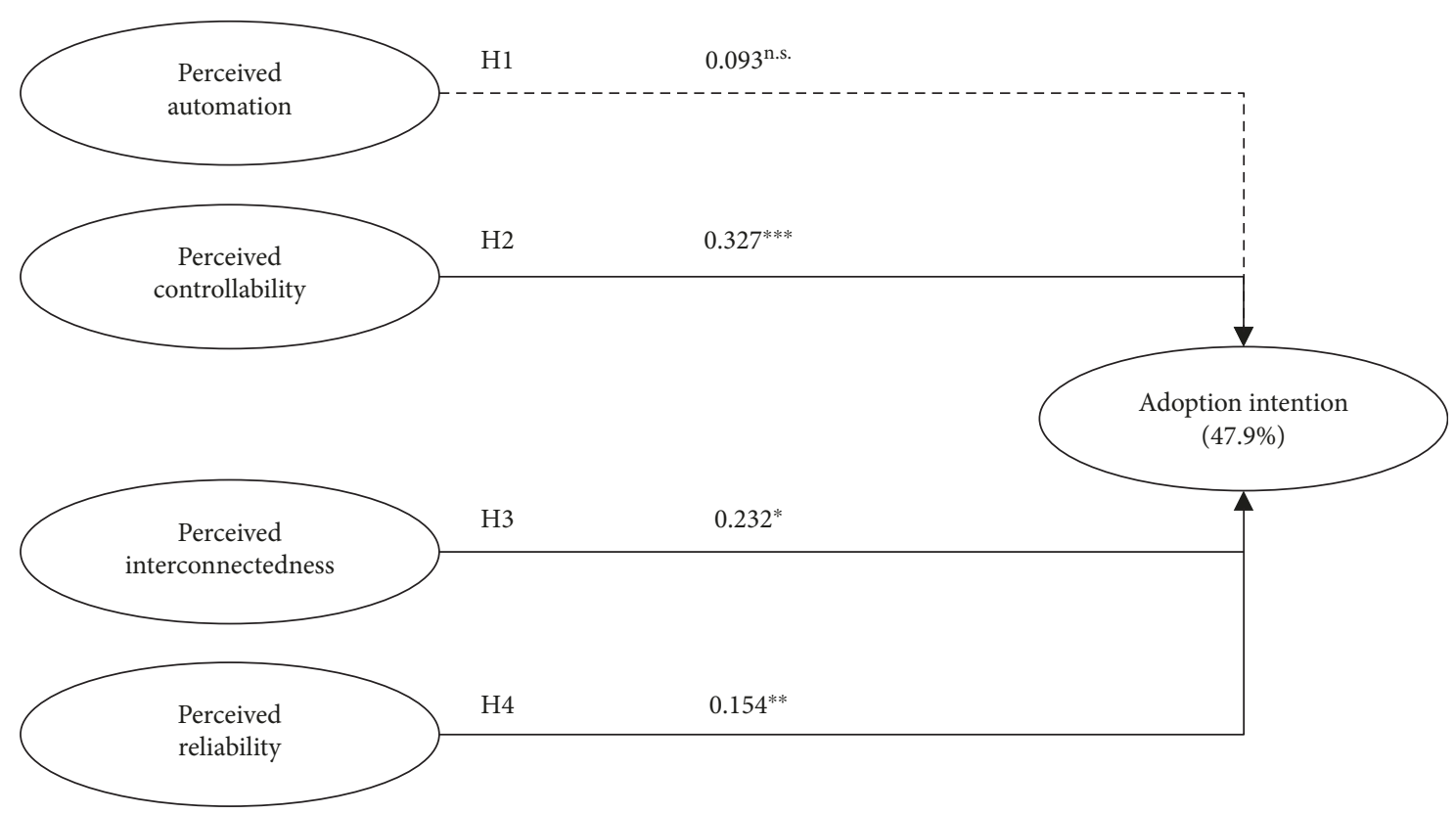

Figure 3: Results of the structural model: ${ }^{*} p<0.05,{ }^{* *} p<0.01$, and ${ }^{* * *} p<0.001$ (two tailed).

TABLE 7: Result of path coefficients by grouping.

\begin{tabular}{|c|c|c|c|c|c|c|c|c|}
\hline & \multicolumn{2}{|c|}{ Residence type $(N)$} & \multicolumn{2}{|c|}{ Gender } & \multicolumn{2}{|c|}{ Age } & \multicolumn{2}{|c|}{ Experience } \\
\hline & APT (114) & House (102) & M (111) & F (105) & $<39(110)$ & $40+(106)$ & Yes (46) & No (170) \\
\hline $\mathrm{H} 1$ & -0.053 & $0.271^{* * *}$ & 0.153 & 0.004 & 0.015 & 0.159 & $0.332^{* *}$ & 0.047 \\
\hline $\mathrm{H} 2$ & $0.367^{*}$ & $0.317^{*}$ & $0.291^{*}$ & $0.378^{* *}$ & $0.256^{*}$ & $0.378^{* *}$ & 0.264 & $0.310^{*}$ \\
\hline $\mathrm{H} 3$ & $0.301^{*}$ & 0.129 & $0.251^{*}$ & 0.217 & $0.337^{*}$ & 0.134 & 0.062 & $0.272^{*}$ \\
\hline $\mathrm{H} 4$ & 0.148 & $0.165^{*}$ & 0.142 & $0.184^{*}$ & 0.157 & $0.177^{*}$ & $0.342^{* *}$ & 0.140 \\
\hline
\end{tabular}

${ }^{*} p<0.05,{ }^{* *} p<0.01$, and ${ }^{* * *} p<0.001$.

want is eventually intelligent and represents an optimal controllability that is close to a limited form of automation.

There are also various findings in group comparison analysis. Controllability and interconnectedness significantly affect adoption for people living in apartments while automation and reliability are considered to be important for general home residents. The difference in the level of infrastructure between apartments and general homes may be an influence. Recently, new apartments in Korea have been provided with smart home services (remote heating management, gas shutdown, etc.). As a result, apartment residents seem to want more extensive and precise control. As general homes do not provide any networked and automated functions to control households, general home residents may want the automation and reliability of a smart home service.

When comparing gender, men emphasize interconnectivity while women emphasize reliability. Similar results were observed in the age-related comparisons. This can be attributed to the risk avoiding tendency of women and older people. It is understandable that they prefer these factors because they seek stability compared to men or young people. Men and young people tend to prefer interesting and innovative services, and the interconnectedness of the smart home can serve as a factor in meeting these needs.
Those who have experienced similar services emphasize automation and reliability. In fact, it is likely that those who do not place much significance on control and interconnection have experienced that the control and connectivity of past services did not guarantee usability.

6.2. Contributions. This study makes several contributions to theory. First, it presents the specific success factors of smart home service adoption and empirically analyzes the relationship with the acceptance behavior. Most studies have presented abstract success factors (e.g., usefulness and enjoyment) based on technology acceptance theory, but this study derived the detailed critical factors through a literature review. Second, this study captures the concept of the word "smart" in the smart home service. According to the result, the smart that people desire is close to intelligent control but not fully automated. This explains why past services (e.g., home automation and the networked home) that are similar to a smart home have not spread. The past services have not been able to meet the desired level of automation for users. Third, the results of the comparison between the groups show that the factors that influence smart home adoption can be different according to the characteristics of users in the case of a smart home 
service. In the case of a smart home service, the main users are often the elderly, patients, and women, and the results clearly show the effect of user characteristics on acceptance behavior. Therefore, acceptance studies that may be different according to user characteristics demonstrate that a research design needs to consider user characteristics.

This study also provides several useful insights for practitioners who manage the development or marketing of a smart home service. First, functional diversity should be assured to consumers. Due to the different smart home service requirements determined by the customer group, it is necessary to systematically support each consumer group in selecting the desired functions. For example, it is possible to provide a smart home service with high interconnectivity with other devices for apartment residents, while focusing on delivering an automation function for general home residents. To this end, smart home service companies should consider how to configure smart home services, including cooperating with third party device manufacturers for each type of customer, and prepare various plans according to the detailed function configuration. Second, continuous $\mathrm{R} \& \mathrm{D}$ on AI-based automation is required. It was revealed that automation has a positive impact on the intention for continuous use of current smart home users. Therefore, it is reasonable to infer that as the basic controllability-based smart home service spreads, consumers' need for automation will increase. A large-scale investment on basic infrastructure such as data centers, cloud, or big data systems by smart home service companies will be required in order to analyze customers' lifestyles and interact with their movements of emotional change. Third, to increase customer reliability, smart home service providers should adopt high-level security technologies and set up internal policies to prevent information leakage. Trust in smart home service providers has become a significant issue as data-based smart home companies are rapidly expanding, such as Google.

\section{Conclusion and Further Study}

This study empirically examined important factors for the adoption and spread of smart home services. Research results show that interconnectivity and reliability are required along with the right level of automation. Furthermore, because there are differences in preference factors according to the characteristics of users, it has been confirmed that the service design that considers these characteristics is necessary. If these factors are taken into consideration, smart home services that have not been activated in the past will spread and the market will grow.

Although the findings of this study provide meaningful insights into the adoption of smart home services, this study has limitations that future research should address. First, key findings of this research are based on the data only from South Korea. A future study should attempt to gather ethnically and geographically diverse data to ensure the generalizability of the results. Second, hedonic-related variables may be considered as influence factors of adoption intention such as perceived design (e.g., visual attractiveness of control hub hardware and software user interface). Lastly, in future studies, a significant difference in the antecedents' influence on behavioral intention between current and potential users may be found. Despite the limitations, this study contributes to a more systematic understanding of smart home service adoption. In this regard, we hope that this study helps to create a foundation for related future research.

\section{Conflicts of Interest}

Authors declare that there is no conflict of interest regarding the publication of this paper.

\section{Acknowledgments}

This study was supported by the BK21+Intellectual Property.Information Protection Law Expert Program.

\section{References}

[1] Y. Nakamura, Y. Arakawa, T. Kanehira, M. Fujiwara, and K. Yasumoto, "SenStick: comprehensive sensing platform with an ultra tiny all-in-one sensor board for IoT research," Journal of Sensors, vol. 2017, Article ID 6308302, 16 pages, 2017.

[2] Mordorintelligence, "Global smart homes market-growth, analysis, forecast to 2022," https://www.mordorintelligence. com/industry-reports/global-smart-homes-market-industry? gclid=CIjd6MXjydYCFYYDKgod4ZQFaw.

[3] V. Ricquebourg, D. Menga, D. Durand, B. Marhic, L. Delahoche, and C. Loge, "The smart home concept: our immediate future," in 2006 1ST IEEE International Conference on E-Learning in Industrial Electronics, pp. 23-28, Hammamet, Tunisia, 2006, IEEE.

[4] W. K. Edwards and R. E. Grinter, "At home with ubiquitous computing: seven challenges," in Ubicomp 2001: Ubiquitous Computing, pp. 256-272, Springer, Berlin, Heidelberg, 2001.

[5] N. Balta-Ozkan, R. Davidson, M. Bicket, and L. Whitmarsh, "Social barriers to the adoption of smart homes," Energy Policy, vol. 63, pp. 363-374, 2013.

[6] R. Lutolf, "Smart home concept and the integration of energy meters into a home based system," in Seventh International Conference on Metering Apparatus and Tariffs for Electricity Supply, pp. 277-278, Glasgow, UK, 1992, IET.

[7] C. Kidd, R. Orr, G. Abowd et al., "The aware home: a living laboratory for ubiquitous computing research," in Cooperative Buildings. Integrating Information, Organizations, and Architecture, pp. 191-198, Springer, Berlin, Heidelberg, 1999.

[8] A. M. Adami, T. L. Hayes, and M. Pavel, "Unobtrusive monitoring of sleep patterns," in Proceedings of the 25th Annual International Conference of the IEEE Engineering in Medicine and Biology Society (IEEE Cat. No.03CH37439), vol. 2, pp. 1360-1363, Cancun, Mexico, 2003, IEEE.

[9] H. Andoh, K. Watanabe, T. Nakamura, and I. Takasu, "Network health monitoring system in the sleep," in SICE 2004 Annual Conference, vol. 2, pp. 1421-1424, Sapporo, Japan, 2004, IEEE.

[10] T. Koskela and K. Väänänen-Vainio-Mattila, "Evolution towards smart home environments: empirical evaluation of three user interfaces," Personal and Ubiquitous Computing, vol. 8, no. 3-4, pp. 234-240, 2004.

[11] A.-G. Paetz, B. Becker, W. Fichtner, and H. Schmeck, "Shifting electricity demand with smart home technologies-an 
experimental study on user acceptance," in 30th USAEE/IAEE North American Conference, vol. 19, p. 20, Washington, DC, USA, 2011.

[12] A. Leeraphong, B. Papasratorn, and V. Chongsuphajaisiddhi, "A study on factors influencing elderly intention to use smart home in Thailand: a pilot study," in The 10th International Conference on e-Business, Bangkok, Thailand, 2015.

[13] A. Alaiad and L. Zhou, "Patients' behavioral intentions toward using WSN based smart home healthcare systems: an empirical investigation," in 2015 48th Hawaii International Conference on System Sciences, pp. 824-833, Kauai, HI, USA, 2015, IEEE.

[14] X. Fan, Q. Xie, X. Li et al., "Activity recognition as a service for smart home: ambient assisted living application via sensing home," in 2017 IEEE International Conference on AI \& Mobile Services (AIMS), pp. 54-61, Honolulu, HI, USA, 2017, IEEE.

[15] L. Vadillo, M. L. Martín-Ruiz, I. Pau, R. Conde, and M. Á. Valero, "A smart telecare system at digital home: perceived usefulness, satisfaction, and expectations for healthcare professionals," Journal of Sensors, vol. 2017, Article ID 8972350, 12 pages, 2017.

[16] H. Bao, A. Y. L. Chong, K. B. Ooi, and B. Lin, “Are Chinese consumers ready to adopt mobile smart home? An empirical analysis," International Journal of Mobile Communications, vol. 12, no. 5, pp. 496-511, 2014.

[17] E. Park, Y. Cho, J. Han, and S. J. Kwon, "Comprehensive approaches to user acceptance of Internet of Things in a smart home environment," IEEE Internet of Things Journal, vol. 4, no. 6, pp. 2342-2350, 2017.

[18] J. Ji, T. Liu, C. Shen et al., "A human-centered smart home system with wearable-sensor behavior analysis," in 2016 IEEE International Conference on Automation Science and Engineering (CASE), pp. 1112-1117, Fort Worth, TX, USA, 2016, IEEE.

[19] S. Tanwar, P. Patel, K. Patel, S. Tyagi, N. Kumar, and M. Obaidat, "An advanced Internet of Thing based security alert system for smart home," in 2017 International Conference on Computer, Information and Telecommunication Systems (CITS), pp. 25-29, Dalian, China, 2017, IEEE.

[20] E. Elmasllari and A. Al-Akkad, "Smart energy systems in private households: behaviors, needs, expectations, and concerns," in 2017 IEEE 14th International Conference on Networking, Sensing and Control (ICNSC), pp. 152-157, Calabria, Italy, 2017, IEEE.

[21] A. La Marra, F. Martinelli, P. Mori, and A. Saracino, "Implementing usage control in internet of things: a smart home use case," in 2017 IEEE Trustcom/BigDataSE/ICESS, pp. 1056-1063, Sydney, NSW, Australia, 2017, IEEE.

[22] H. Ghayvat, S. Mukhopadhyay, X. Gui, and N. Suryadevara, "WSN- and IOT-based smart homes and their extension to smart buildings," Sensors, vol. 15, no. 5, pp. 10350-10379, 2015.

[23] S. Sintonen and M. Immonen, "Telecare services for aging people: assessment of critical factors influencing the adoption intention," Computers in Human Behavior, vol. 29, no. 4, pp. 1307-1317, 2013.

[24] R. Parasuraman and V. Riley, "Humans and automation: use, misuse, disuse, abuse," Human Factors, vol. 39, no. 2, pp. 230-253, 1997.

[25] C. Reinisch, M. J. Kofler, and W. Kastner, "ThinkHome: a smart home as digital ecosystem," in 4th IEEE International
Conference on Digital Ecosystems and Technologies, pp. 256261, Dubai, UAE, 2010, IEEE.

[26] A. Geraci, F. Katki, L. McMonegal et al., IEEE Standard Computer Dictionary: Compilation of IEEE Standard Computer Glossaries, IEEE Press, Piscataway, NJ, USA, 1991.

[27] M. Chan, D. Estève, C. Escriba, and E. Campo, "A review of smart homes-present state and future challenges," Computer Methods and Programs in Biomedicine, vol. 91, no. 1, pp. 5581, 2008.

[28] M. Sági, D. Mijic, D. Milinkov, and B. Bogovac, "Smart home automation," in 2012 20th Telecommunications Forum (TELFOR), pp. 1512-1515, Belgrade, Serbia, 2012, IEEE.

[29] T. T. Luor, H.-P. Lu, H. Yu, and Y. Lu, "Exploring the critical quality attributes and models of smart homes," Maturitas, vol. 82, no. 4, pp. 377-386, 2015.

[30] R. Kalman, "On the general theory of control systems," IRE Transactions on Automatic Control, vol. 4, no. 3, p. 110, 1959.

[31] Y.-Y. Liu, J.-J. Slotine, and A.-L. Barabási, "Controllability of complex networks," Nature, vol. 473, no. 7346, pp. 167-173, 2011.

[32] J. Choi, H. J. Lee, F. Sajjad, and H. Lee, "The influence of national culture on the attitude towards mobile recommender systems," Technological Forecasting and Social Change, vol. 86, no. 1, pp. 65-79, 2014.

[33] K. Lyytinen and Y. Yoo, "Research commentary: the next wave of nomadic computing," Information Systems Research, vol. 13, no. 4, pp. 377-388, 2002.

[34] C. Kühnel, T. Westermann, F. Hemmert, S. Kratz, A. Müller, and S. Möller, "I'm home: defining and evaluating a gesture set for smart-home control," International Journal of Human-Computer Studies, vol. 69, no. 11, pp. 693-704, 2011.

[35] C. Roduner, M. Langheinrich, C. Floerkemeier, and B. Schwarzentrub, "Operating appliances with mobile phones-strengths and limits of a universal interaction device," in International Conference on Pervasive Computing, pp. 198-215, Toronto, ON, Canada, 2007, Springer.

[36] M. Pagani, "Determinants of adoption of third generation mobile multimedia services," Journal of Interactive Marketing, vol. 18, no. 3, pp. 46-59, 2004.

[37] H. Yang, J. Yu, H. Zo, and M. Choi, "User acceptance of wearable devices: an extended perspective of perceived value," Telematics and Informatics, vol. 33, no. 2, pp. 256-269, 2016.

[38] A. H. Maslow, "A theory of human motivation," Psychological Review, vol. 50, no. 4, pp. 370-396, 1943.

[39] P. Keen, G. Ballance, S. Chan, and S. Schrump, Electronic Commerce Relationships: Trust by Design, Prentice Hall PTR, Upper Saddle River, NJ, USA, 1999.

[40] M. Friedewald, O. D. Costa, Y. Punie, P. Alahuhta, and S. Heinonen, "Perspectives of ambient intelligence in the home environment," Telematics and Informatics, vol. 22, no. 3, pp. 221-238, 2005.

[41] W. W. Chin and J. Dibbern, "An introduction to a permutation based procedure for multi-group PLS analysis: results of tests of differences on simulated data and a cross cultural analysis of the sourcing of information system services between Germany and the USA," in Handbook of Partial Least Squares, pp. 171-193, Springer, Berlin, Heidelberg, 2010.

[42] J. C. Augusto and C. D. Nugent, "Smart homes can be smarter," in Designing Smart Homes, pp. 1-15, Springer, Berlin, Heidelberg, 2006. 
[43] S. Hammer, M. Wißner, and E. André, "Trust-based decision-making for smart and adaptive environments," User Modeling and User-Adapted Interaction, vol. 25, no. 3, pp. 267-293, 2015.

[44] M.-H. Hsu and C.-M. Chiu, "Internet self-efficacy and electronic service acceptance," Decision Support Systems, vol. 38, no. 3, pp. 369-381, 2004.

[45] B. Van der Vlist, G. Niezen, J. Hu, and L. Feijs, "Design semantics of connections in a smart home environment," in Proceedings of Design and Semantics of Form and Movement (DeSForM), pp. 48-56, Lucerne, Switzerland, 2010.

[46] H. Yang, H. Lee, and H. Zo, "User acceptance of smart home services: an extension of the theory of planned behavior," Industrial Management \& Data Systems, vol. 117, no. 1, pp. 68-89, 2017.

[47] P. Meso, P. Musa, and V. Mbarika, "Towards a model of consumer use of mobile information and communication technology in LDCs: the case of sub-Saharan Africa," Information Systems Journal, vol. 15, no. 2, pp. 119-146, 2005.

[48] F. D. Davis, R. P. Bagozzi, and P. R. Warshaw, "User acceptance of computer technology: a comparison of two theoretical models," Management Science, vol. 35, no. 8, pp. 982-1003, 1989.

[49] W. Bhuasiri, H. Zo, H. Lee, and A. P. Ciganek, "User acceptance of e-government services: examining an e-tax filing and payment system in Thailand," Information Technology for Development, vol. 22, no. 4, pp. 672-695, 2016.

[50] J. C. Anderson and D. W. Gerbing, "Structural equation modeling in practice: a review and recommended two-step approach," Psychological Bulletin, vol. 103, no. 3, pp. 411423, 1988.

[51] C. Fornell and D. F. Larcker, "Structural equation models with unobservable variables and measurement error: algebra and statistics," Journal of Marketing Research, vol. 18, no. 3, pp. 382-388, 1981. 


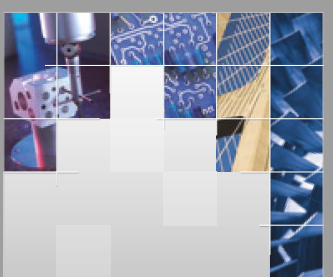

\section{Enfincering}
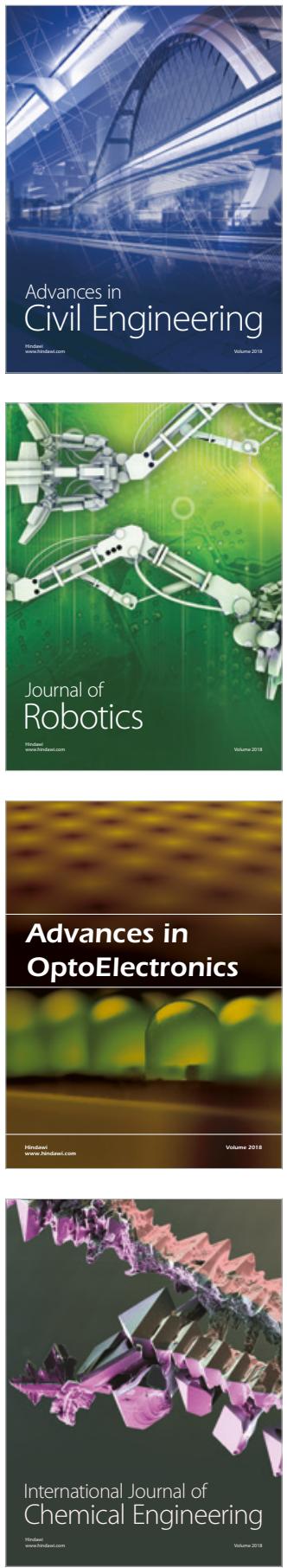

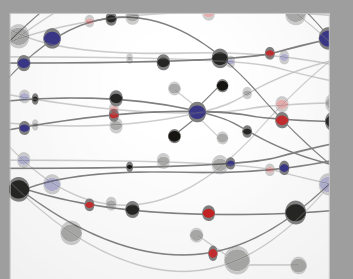

\section{Rotating \\ Machinery}

The Scientific World Journal

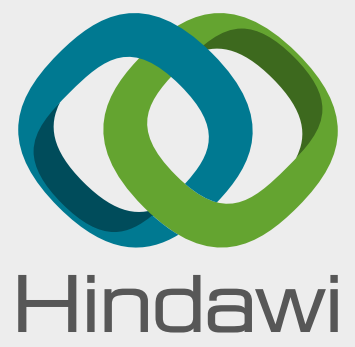

Submit your manuscripts at

www.hindawi.com
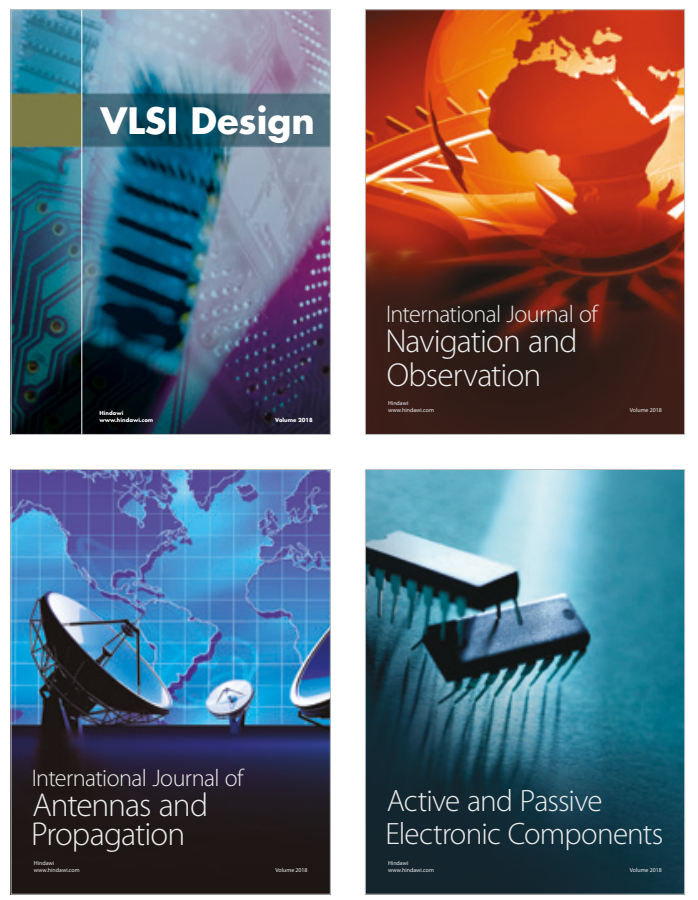
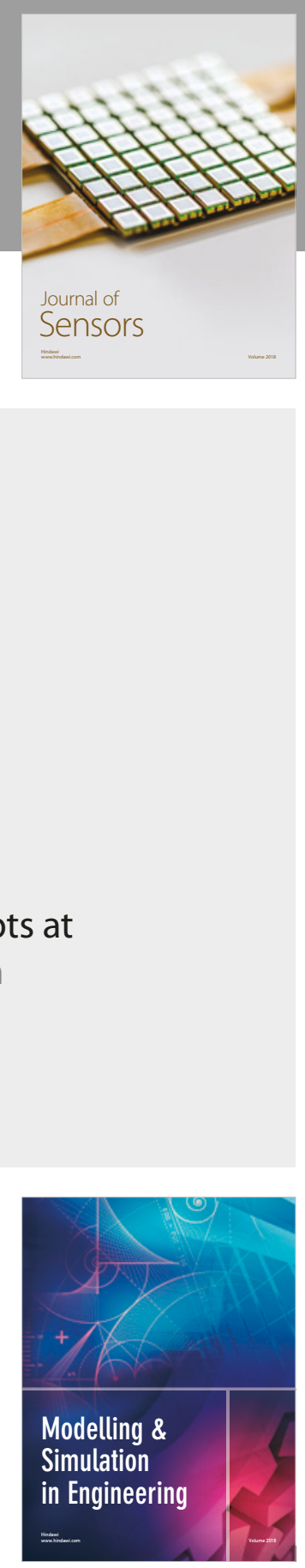

\section{Advances \\ Multimedia}
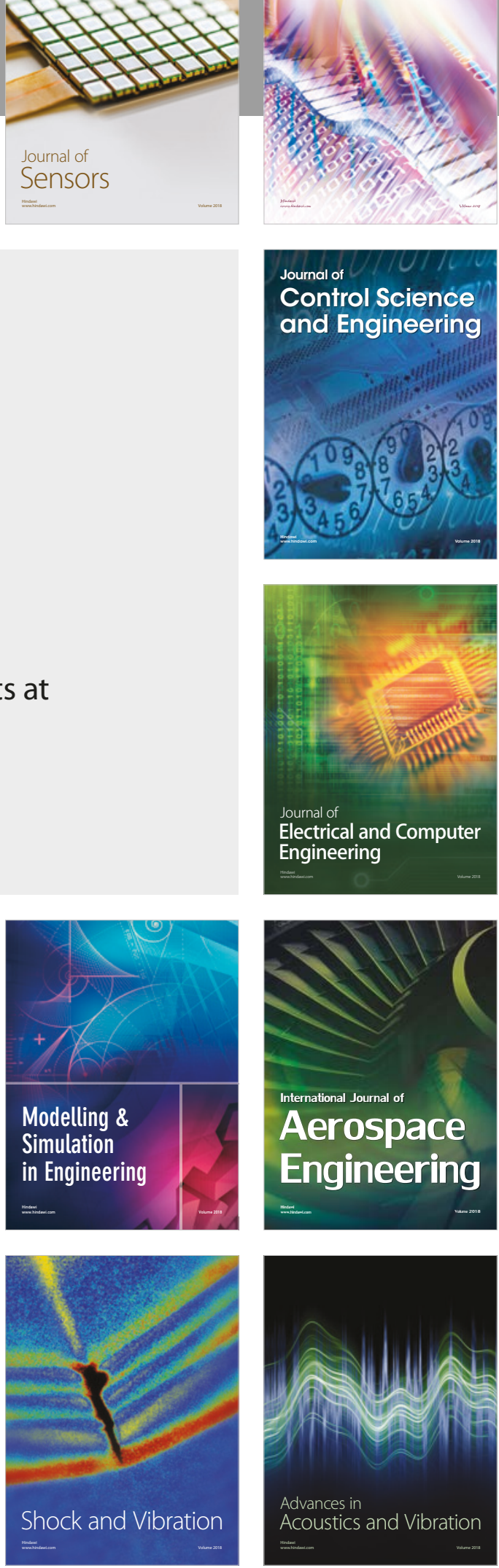